\title{
Educationally Critical Characteristics of Deep Approaches to Learning about the Concept of an Information System
}

\author{
Chris Cope \\ La Trobe University, Bendigo, Australia
}

c.cope@latrobe.edu.au

Executive Summary

This paper reports on an empirical study investigating the relationship between the approaches to learning and levels of understanding of the concept of an information system (IS) in undergraduate IS students. The findings show educationally critical characteristics of the learning approaches that lead to the development of a deep understanding. Knowledge about these critical characteristics can be used to design learning activities likely to encourage IS students to use effective learning approaches.

Underlying the study are findings from student learning research. This research investigated students' perceptions of their own learning experiences. Consistent findings have been that students' approaches to learning about key disciplinary concepts can be categorized as either surface or deep. Only deep learning approaches have been associated with the development of deep levels of understanding. Deep learning approaches have been found to have educationally critical characteristics, the detail of which is different for each concept.

Learning about the concept of an IS has not been studied as part of the student learning research. Consequently, knowledge is lacking about the critical characteristics of the deep learning approaches likely to lead to the development of a deep understanding of the concept of an IS. A deep understanding of the concept of an IS has been proposed elsewhere as viewing an IS as a social system of people making meaningful organizational decisions supported by embedded information technology (IT).

In the empirical study, the interview transcripts and questionnaires of 112 undergraduate students learning about IS for a year were classified individually as representing either a surface or deep approach to learning, and a particular level of understanding of the concept of an IS. The classifications were analyzed statistically to investigate the existence and nature of any relationship between approach to learning and level of understanding.

Only certain deep approaches to learning about IS were associated with levels of understanding that incorporated social aspects of the concept of an IS. The educationally critical aspects of these deep learning approaches were found to be:

1. an intention to seek a deep understanding of the concept of an IS.

Material published as part of this journal, either on-line or in print, is copyrighted by the publisher of the Journal of Information Technology Education. Permission to make digital or paper copy of part or all of these works for personal or classroom use is granted without fee provided that the copies are not made or distributed for profit or commercial advantage AND that copies 1) bear this notice in full and 2) give the full citation on the first page. It is permissible to abstract these works so long as credit is given. To copy in all other cases or to republish or to post on a server or to redistribute to lists requires specific permission and payment of a fee. Contact Editor@JITE.org to request redistribution permission.
2. the process of seeking and relating the meanings associated with a broad range of different perspectives on the concept of an IS, including perspectives in personal experiences beyond the academic setting and in studies outside IS and computing courses.

3. an awareness of one's own understanding of the concept of an IS and the approaches being used to learn about IS. 
Based on these characteristics, the nature of learning activities likely to encourage students to use a deep approach to learning about IS is proposed. Learning activities should centre on students being aware of and taking charge of their own approaches to developing a deep understanding of the concept of an IS.

Keywords : Information systems education, student learning, phenomenography, deep learning approaches.

\section{Introduction}

In some educational disciplines studies have investigated how best to teach and learn key concepts (for example, mathematics - Crawford, Gordon, Nicholas, \& Prosser, 1994, 1998; biology - Hazel, Prosser \& Trigwell, 1996, 2002; physics - Prosser \& Millar, 1989). A consistent finding has been that only certain learning approaches lead to the development of a deep understanding. These learning approaches have been found to have educationally critical characteristics that are similar in general but different in detail for each particular concept (Booth, 1997; Marton \& Booth, 1996; McCune \& Entwistle, 2000). Knowledge about the detail would seem vital to improving teaching and learning about a particular concept. Learning tasks can then be designed that encourage and favor the use of appropriate learning approaches.

A key concept in the IS discipline is the concept of an information system (IS). It seems logical that undergraduate IS students should be exploring the nature of an IS in depth with the aim of developing a deep understanding. To achieve this deep understanding the research in other disciplines suggests that IS students should be using learning approaches with certain educationally critical characteristics that are specific to learning about the concept of an IS. Yet, the detail of these educationally critical characteristics has not appeared previously in the IS education research literature. This would seem to be a significant impediment to ensuring the quality of IS students' learning outcomes.

This paper reports one section of a large empirical study of IS undergraduate students' learning experiences. The section investigated the educationally critical characteristics of learning approaches likely to lead to the development of a deep understanding of the concept of an IS. The findings have significant implications for IS undergraduate education.

\section{Background}

One of the most powerful contributions to improving the quality of students' learning outcomes in higher education has been made by the student learning research (Biggs, 1999). This research has investigated students' and teachers' perceptions of their own experiences of learning environments. A research approach frequently used in the student learning research has been phenomenography - a qualitative approach that attempts to describe broad variation in small groups of peoples' experiences of a phenomenon in the world (see Marton \& Booth, 1997 for more detail). The broad variation has been described in the form of an outcome space of a limited number of critically different but hierarchically related categories of description of a phenomenon. Phenomenography has been especially useful in the study of student learning. The categories of description higher in a hierarchy have been shown logically to be associated with better quality learning outcomes. The differences between categories of description have proven to be educationally critical ones. Analyzing these critical differences has provided insights into how teaching and learning can be structured to bring about high quality learning (Cope, 2000a; Marton \& Booth, 1997).

Two phenomena studied extensively in the student learning research using phenomenographic research approaches have been level of understanding of key disciplinary concepts and approach to learning. As an example of the consistent findings, the study of students' experiences of learning about the concept of an IS that underlies the empirical study reported later in this paper will be used (Cope, 2000a). One hundred and twelve students learning about IS for a year in the middle of an undergraduate computing de- 
gree were involved in data collection through in-depth interviews and questionnaires. The data collection instruments explored students' levels of understanding of the concept of an IS and approaches to learning about IS. All quotes on the transcribed interviews and questionnaires were pooled and analyzed using phenomenographic techniques (for detail of these techniques see Booth, 1997, p. 138; Cope, 2002b, p. 71; Marton \& Booth, 1997, p. 129).

An outcome space of six distinctly different but hierarchically related categories of description of the concept of an IS was identified in a prior study (Cope, 2000a, 2000b, 2002a) (Table 1). The hierarchy was based on inclusiveness and level of understanding. Categories of description higher in the hierarchy (categories 5 and 6) were inclusive of and represented a deeper level of understanding of the concept of an IS than those lower in the hierarchy. Categories of description higher in the hierarchy involved an awareness of more related aspects of an

IS and delimited an IS as a broader entity within an organization. There was a logical break in the hierarchy between categories 4 and 5. Categories of description 1 through 4 represented IT-only views of an IS. Categories of description 5 and 6 included people and some data-related processes they performed as well as IT in the IS. Categories 5 and 6 were more consistent with the view argued extensively in the literature that IS should be considered as social systems of people making decisions supported by IT embedded in the system (Beynon-Davies, 1998; Callaos \& Callaos, 2002; Cope, 2000a, 2000b, 2002a; Falkenberg et al., 1996; Land, 1992; Winter, Brown \& Checkland, 1995).

The study identified two distinctly different categories of description of approach to learning about IS.

\begin{tabular}{|c|c|}
\hline Category & Meaning \\
\hline 6 & $\begin{array}{l}\text { A number of communicating information sys- } \\
\text { tems within a single organization }\end{array}$ \\
\hline 5 & $\begin{array}{l}\text { A computerised data manipulation system } \\
\text { and people gathering data, disseminating in- } \\
\text { formation and communicating to support a } \\
\text { single organizational function. }\end{array}$ \\
\hline 4 & $\begin{array}{l}\text { A computerised data manipulation system } \\
\text { supporting many people within a single or- } \\
\text { ganizational function. }\end{array}$ \\
\hline 3 & $\begin{array}{l}\text { A data manipulation system supporting an } \\
\text { individual within a single organizational } \\
\text { function }\end{array}$ \\
\hline 2 & A simple information retrieval system. \\
\hline 1 & $\begin{array}{l}\text { A personal search of a static information } \\
\text { source }\end{array}$ \\
\hline
\end{tabular}

Table 1. Categories of description of the concept of an IS (Cope, 2002a)

\section{A. Surface approach to learning about IS}

In this category, approaching learning about IS involved a series of isolated and generally unrelated learning and assessment tasks that had to be completed successfully to satisfy academic achievement requirements and progress in the course. Each learning task was viewed as a potential source of knowledge that needed to be acquired to meet the assessment requirements. Knowledge was variously experienced as facts contained in lecture notes and summaries, formulae, how and when to apply formulae, tactics to solve problems, skills, how to use software, etc. Acquiring this knowledge involved either an active, intentional process of memorizing the content or a less active process of gaining knowledge through absorbing the content, having it sink in, taking it in. The intention of acquiring the knowledge was to be able to recall or apply it in assessment situations. In some instances the intention was to be able to directly recall the knowledge. In other instances, the intention was to be able to apply memorized procedures, problem solving approaches, software instructions, and so forth

\section{B. Deep approach to learning about IS}

In this category, approaching learning about IS involved seeking the meaning of the content encountered in the learning tasks and assignments with the intent of developing or deepening understanding. Learn- 
ing and assignment tasks were not seen as external impositions - merely hurdles to be jumped in the race to obtain a degree. Rather they involved some content that had a meaning beyond the immediate task. The learning approach included a motivation to seek this meaning as a part of learning in the academic setting and for personal reasons beyond the academic setting. Meaning, and consequently understanding, were sought through relating the content associated with learning and assignment tasks to the content in the same or other courses (both IS courses and other computing courses). There was variation in the experience of having an understanding. In some instances, an understanding meant having a clear picture, a completed puzzle, a scenario, one's own version of the content. In other variations, an understanding formed a background that could be used to link new material or allowed a concept to be explained to others off the top of the head.

The findings of Cope's (2000a) study of students' experiences of learning about the concept of an IS were consistent with the findings of many other phenomenographic studies of students' learning experiences. These studies have consistently shown that a phenomenon can be understood at a limited number of qualitatively different but hierarchically related levels (for example, Crawford et al., 1994; Johansson, Marton \& Svensson, 1995; Lybeck, Marton, Stromdahl, \& Tullberg, 1988; Prosser \& Millar, 1989). The two qualitatively different approaches to learning are consistent with the surface and deep learning approaches described in many other situations (for example, Booth, 1992; Crawford et al., 1994; Eizenberg, 1988; Entwistle \& Ramsden, 1983; Hazel \& Prosser, 1994). Both surface and deep learning approaches have been found to allow for a number of preferred learning styles but the intention with which a learning style is applied is the key to distinguishing the approaches. The intention of a surface learning approach is to recall isolated pieces of knowledge and procedures in assessment situations. The intention of a deep learning approach is to develop a personal understanding (see Prosser \& Trigwell, 1999 for more detail).

In some of these other studies, the existence and nature of a relationship between approach to learning and level of understanding has also been investigated (for example, Crawford et al., 1994; Hazel \& Prosser, 1994; Hazel, Prosser \& Trigwell, 1996; Marton \& Säljö, 1976; Prosser, 1994; Prosser \& Millar, 1989; Trigwell \& Prosser, 1991). Data for investigating the relationship ha ve typically been generated in two ways. First, the level of understanding or approach to learning underlying each interview transcript or questionnaire as a whole has been classified against the appropriate outcome space developed in the phenomenographic study. Secondly, generic questionnaires have been generated from the findings and used on large numbers of students (for example, ASI - Entwistle \& Ramsden, 1983; SPQ - Biggs, 1987a, 1987b; ASSIST - Tait \& Entwistle, 1996). The findings have been remarkably consistent. Surface learning approaches have been associated with lower levels of understanding of a phenomenon, and deep learning approaches, deeper levels of understanding.

The establishment of a relationship between approach to learning and level of understanding of a key concept has allowed student learning researchers to investigate the nature of learning approaches that have been associated with the development of deeper levels of understandings. The insights obtained have resulted in the design and implementation of learning tasks that aim to encourage students to use deep learning approaches. A complication has been that while there are some general characteristics of all deep learning approaches, certain key characteristics have been found to vary from context to context, for example, key concept (Crawford et al, 1994; Eizenberg, 1988) and learning task (Hodgson, 1984; Marton \& Säljö, 1976; Svensson, 1977). These key characteristics are likely to be educationally critical to the learning approach. Unless these characteristics are part of a student's learning approach the deve lopment of a deep understanding is unlikely (Booth, 1997; Cope, 2000a).

Learning about the concept of an IS has not been studied as part of the student learning research. The educationally critical characteristics of approaches to learning likely to lead to the development of a deep understanding of the concept of IS are not known. To obtain this knowledge requires investigating empirically whether a relationship exists between approach to learning and level of understanding of the 
concept of an IS and then, logically analyzing the critical characteristics of the learning approaches found to lead to the development of a deep understanding. The existence of a relationship between approach to learning and level of understanding of the concept of an IS cannot be taken for granted on the basis of studies of other key concepts. The concept of an IS has a different nature to the majority of concepts studied. The concept of an IS is not well defined and is also multi-facetted, comprising many other related concepts, for example a database, a user interface and attribution of meaning (Cope, 2002a). Contrast this with studies of the relationship between learning approach and level of understanding of well-understood concepts such as states of matter (Renström, Andersson \& Marton, 1990), mechanics (Bowden et al., 1992), motion (Prosser \& Millar, 1989) or photosynthesis (Hazel, Prosser \& Trigwell, 1996).

Consequently, the research questions addressed in the empirical study reported next in this paper were, "Is there a relationship between approach to learning and level of understanding of the concept of an IS?" and, if so, "What is the nature of the relationship?" The findings of the empirical study were then analyzed logically to gain insights into the educationally critical characteristics of approaches to learning likely to lead to the development of a deep understanding of the concept of an IS.

\section{Method}

Data for the investigation of the research questions were obtained from the 38 interview transcripts and 202 questionnaires from the larger study of undergraduate students' experiences of learning about IS (Cope, 2000a). Broadly the study reported here involved classifying the level of understanding of the concept of an IS and approach to learning about IS underlying each questionnaire and interview transcript against the outcome spaces of the larger study. The classifications were then analyzed statistically.

The participants in the study were recruited from all students present in a lecture at the beginning of the year of study about IS. Students were told the purpose of the study, that participation was voluntary, and responses would be anonymous. Those students that subsequently completed a questionnaire involving short written answers became part of the study. A method was devised for uniquely identifying each questionnaire that guaranteed anonymity but also allowed questionnaires completed by the same student at different times of the study to be matched. Students were asked to fill in a key on each questionnaire. The key consisted of the sum of the digits in the student's ID number, the sum of the digits in the student's date of birth and the student's mother's maiden name. Any two components of the key were likely to uniquely identify a questionnaire.

Table 2 shows the number of questionnaires completed at the beginning, middle and end of the year of study and the number of matching questionnaires. For instance, 81 questionnaires were collected at the beginning of the year of study and 62 in the middle. Of the 62 questionnaires collected in the middle of the study, 58 could be matched with questionnaires from the beginning of the year. A total of 112 students completed at least one of the three que stionnaires.

Interviews took place at the beginning and end of the year of study about IS. Participants came from the pool of students who initially participated in the questionnaire aspect of the study. The questionnaire handed to all students present in the first lecture at the beginning of the year of study also asked for volunteers for the interview part of the study. Students were informed that they could not be anonymous for this part of the study as they needed to be con-

\begin{tabular}{|c|c|c|c|}
\hline & \multicolumn{3}{|c|}{ When administered } \\
\hline & Beginning & Middle & End \\
\hline $\begin{array}{l}\text { Number of stu- } \\
\text { dents enrolled }\end{array}$ & 90 & 86 & 80 \\
\hline $\begin{array}{l}\text { Number of com- } \\
\text { pleted question- } \\
\text { naires }\end{array}$ & 81 & 62 & 59 \\
\hline $\begin{array}{l}\text { Retained from } \\
\text { original sample }\end{array}$ & & 58 & 32 \\
\hline
\end{tabular}

Table 2: Number of questionnaires completed at each data collection 
tacted at the end of the year for more interviews. The students were given a guarantee that a pseudonym would be attached to their interview transcripts and any extracts used in publications. Students were told that ethics approval had been given and details of a contact person were provided should issues of bias in assessment marking be considered a concern. Twenty-three students volunteered for the interviews at the beginning of the year of study and 15 of those were interviewed again at the end.

As the sample of students involved in the interviews and questionnaires was one made up of volunteers, detail of the sample needs to be provided. Consideration of the generalizability of the results of the empirical study needs to occur in the light of the nature of the sample. The breakdown of the initial interview sample of 23 students was 20 males and 3 females, 15 students straight from secondary education and 8 mature age students, 17 students undertaking a single computing degree and 6 undertaking a double degree in computing and business. The double degree had a significantly higher entry requirement than the single degree. Four of the students had studied IS as part of their secondary school education.

The breakdown of the 15 students interviewed again at the end of the year of study was 12 males and 3 females, 10 students straight from secondary education and 5 mature age students, 9 students undertaking a single computing degree and 6 undertaking the double degree. Four of these students had studied IS as part of their secondary school education.

The number of participants involved in the empirical study was consistent with requirements expressed in the literature. With regard to phenomenographic studies, Sandberg (1994) suggests that 20 participants involved in in-depth interviews is generally accepted as sufficient to achieve the required richness of description of the different categories of description of the phenomenon of interest. With reference to in-depth interviews in qualitative research in general, Gay (1992), suggests 30 participants is adequate. Based on these suggestions, the 23 participants in the interviews and 112 students completing at least one questionnaire constituted an adequate sample size.

The data required to investigate the relationship between level of understanding and approach to learning about the concept of an IS was obtained by classifying each interview transcript and questionnaire against the relevant outcome space. As each transcript or questionnaire was read, the level of understanding of the concept of an IS and approach to learning an IS underlying the document as a whole was considered. In many cases a number of different levels of understanding of the concept of an IS, for instance, were represented in a single document. In this circumstance the document was classified against the deepest level of understanding clearly established to the researcher's satisfaction.

The reliability of the classifications was checked in a process that involved another researcher classifying ten questionnaires and five interview transcripts. The questionnaires and interview transcripts were chosen to represent a variety of levels of understanding of the concept of an IS and approaches to learning about IS. Consultation occurred over differences in classifications and changes were made where appropriate. The results of this check are summarized in Table 3.

Once the classification of transcripts and questionnaires had been achieved, the existence of a relationship between level of understanding and approach to learning was investigated. A statistical analysis was undertaken of snapshots of the questionnaire classifications at the beginning, middle and end of the year of study and interview transcript classifications at the beginning and end of the year of study. The existence of a relationship was investigated separately for the interview and questionnaire data because of the possibility of some students being involved in both the questionnaires and interviews. The anonymous nature of the

\begin{tabular}{|c|c|c|}
\hline & $\begin{array}{c}\text { Level of } \\
\text { understanding }\end{array}$ & $\begin{array}{l}\text { Approach to } \\
\text { learning about } \\
\text { IS }\end{array}$ \\
\hline $\begin{array}{l}\text { Percentage agreement } \\
\text { before consultation }\end{array}$ & 73 & 87 \\
\hline $\begin{array}{l}\text { Percentage agreement } \\
\text { after consultation }\end{array}$ & 87 & 93 \\
\hline
\end{tabular}

Table 3: Reliability of classification of five interview transcripts and ten questionnaires 
data collection precluded knowing the number and identity of these students.

The nature of the relationship between approach to learning and level of understanding was investigated in two ways:

1. A statistical analysis of interview and questionnaire data concerning change in level of understanding of the concept of an IS over the year in relation to learning approach was undertaken. In the outcome space depicting a hierarchy of increasingly levels of understanding of the concept of an IS, for instance, an increase of one step up the hierarchy was labeled as $+1,2$ steps +2 , no change 0 , etc.

This is an ordinal scale, with no arithmetic relationship between the values. The question considered was "Is there a significant relationship between amount of change in level of understanding of the concept of an IS and learning approach used?"

2. A more detailed statistical analysis of some of the snapshots was undertaken. In studying the outcome spaces, a logical relationship was hypothesized between the deep learning approach and the categories of description that viewed an IS as including aspects of a social system (categories 5 and 6 in Table 1). The detailed investigation of some of the snapshots sought empirical evidence to support the logical relationship.

All investigations initially involved cross-tabulating the counts of the classifications. Table 4 is an example of the cross-tabulation generated for the data obtained from the questionnaires at the end of the year of study.

The relationships between the crosstabulated variables were investigated using exact statistical techniques. The nature of these techniques is described by Babinec and Mehta (1999):

For a given dataset and test situation, one can in principle generate a reference set of like data of which the observed data are a particular realization. Having generated repeated realizations, one is in a position to know how discrepant the observed data are relative to a "universe" of like data. The fraction of possible realizations at least as discrepant as the observed data gives rise to an exact $\mathrm{p}$-value.

\begin{tabular}{lccccccc}
\hline & \multicolumn{5}{c}{$\begin{array}{c}\text { Level of understanding of an IS } \\
\text { Category }\end{array}$} & \\
\cline { 2 - 6 } $\begin{array}{l}\text { Learning } \\
\text { Approach }\end{array}$ & 1 & 2 & 3 & 4 & 5 & 6 & Totals \\
\hline Surface & 1 & 11 & 27 & 13 & & 51 \\
Deep & 1 & & 1 & 4 & 2 & 8 \\
Total & 1 & 11 & 28 & 17 & 2 & 59 \\
\hline
\end{tabular}

Table 4: Cross-tabulation of counts of level of understanding of the concept of an IS and approach to learning about IS from the classifications of questionnaires at the end of the year of study about IS

An exact $p$-value is more accurate than a $p$ value generated using techniques that assume certain distributions in the data for small data sets and/or heavily skewed data and/or data with lots of ties. Exact pvalues have been able to be calculated for $2 \times 2$ contingency tables using a Fisher Exact test but recent improvements in algorithms and computational power have allowed exact p-values to be calculated for larger size tables. Kendall's tau-b co-efficient was used as a measure of association appropriate for the ordinal variables being investigated (Cooper \& Schindler, 1998).

It is worth noting here that although there is some randomness to the sample in this study, the sample was, by necessity, a convenience one. Consequently, the $\mathrm{p}$ values should be treated with caution as ind icators of the replicability of results. Such statistics are normally given in studies of this nature and this convention is followed here. Inferences from associations found with these convenience samples to other populations are not appropriate. It is also worth noting, ho wever, that the characteristics of the convenience sample, based on experience, are typical of groups of students taking introductory IS subjects in universities similar to La Trobe University. The characteristics of the students being interviewed have been detailed previously in the paper to allow the reader to make judgments on the nature of the sample and the applicability of the statistical results. 


\section{Results}

The existence of a relationship between approach to le arning and level of understanding was investigated in a series of snapshots. A statistically significant association was found in the middle questionnaires (Kendall's tau-b $=.298, p=.008)$, end questionnaires (Kendall's tau-b $=.295, p=.015$ ) and end interviews (Kendall's tau-b $=.634, \mathrm{p}=.007$ ). In the group of students studied, the deep learning approach was strongly associated with the deeper levels of understanding and the surface learning approach with lower levels of understanding.

The nature of the relationship was firstly explored through investigating the relationship between change in level of understanding of the concept of an IS and learning approach. The change in level of understanding over time was statistically significant for the matched beginning and middle questionnaires (Wilcoxon Signed Ranks Test $\mathrm{Z}=-3.319, \mathrm{p}=.000$ ), the matched beginning and end questionnaires (Wilcoxon Signed Ranks Test $Z=-4.456, p=.000$ ), and the matched beginning and end interviews (Wilcoxon Signed Ranks Test $Z=-2.994, p=.000$ ). Given the significance of the change, the amount of change in level of understanding was then found to be statistically associated with approach to learning for the matched beginning and middle questionnaires (Kendall's tau-b $=.273, p=.025$ ), the matched beginning and end questionnaires (Kendall's tau $\mathrm{b}=.564, \mathrm{p}=.001$ ) and the matched beginning and end interviews (Kendall's tau- $\mathrm{b}=.466, \mathrm{p}=.042$ ). The deep learning approach was associated with the greatest positive change in level of understanding of the concept of an IS.

The nature of the relationship between learning approach and level of understanding was then investigated in more detail. The six categories of description of the concept of an IS were divided progressively into two groups and the relationship between the two groups and approach to learning investigated. This investigation sought empirical evidence to support the logical contention that the deep learning approach would be associated with the levels of understand ing incorporating aspects of an IS as a social system (categories of description 5 and 6). The results of this investigation are summarized in Table 5.

For the middle questionnaire data, no statistically significant associations were found at the 5\% level between level of understanding and approach to learning for any groupings of the categories of description. This finding does not support the logical association between the deep learning approach and categories of description 5

and 6. For the end questionnaire data, a statistically significant association was found between level of understanding and approach to learning when considering the different levels of understanding in two groups split at the division between categories 3 and 4 (Kendall's tau-b $=.363$, $\mathrm{p}=.010)$ and again between categories 4 and 5 (Kendall's taub $\mathrm{b}=.473$, $\mathrm{p}=.016)$. The association with the categories grouped on a division between categories 4 and 5 supports the logi-

\begin{tabular}{|c|c|c|c|c|c|}
\hline \multirow[b]{3}{*}{ Statistical measures } & \multirow{2}{*}{\multicolumn{5}{|c|}{$\begin{array}{l}\text { Level of understanding of the concept of an IS } \\
\text { Category groupings }\end{array}$}} \\
\hline & & & & & \\
\hline & $1 / 23456$ & $12 / 3456$ & $123 / 456$ & $1234 / 56$ & $12345 / 6$ \\
\hline \multicolumn{6}{|c|}{ Middle questionnaire $(\mathrm{n}=62)$} \\
\hline Kendall's tau-b & & .251 & .254 & .391 & \\
\hline $\mathrm{p}$ & & .076 & .081 & .097 & \\
\hline \multicolumn{6}{|c|}{ End questionnaire $(\mathrm{n}=59)$} \\
\hline Kendall's tau-b & -.332 & .077 & .363 & .473 & \\
\hline $\mathrm{p}$ & .136 & .680 & .010 & .016 & \\
\hline \multicolumn{6}{|c|}{ End interview $(\mathrm{n}=15)$} \\
\hline Kendall's tau-b & & & .302 & .516 & .784 \\
\hline $\mathrm{p}$ & & & .515 & .022 & .029 \\
\hline
\end{tabular}

Table 5: Summary of statistical analysis of relationship between levels of understanding of the concept of an IS combined into two groups and approach to learning 
cal association between the deep learning approach and deeper levels of understanding of the concept of an IS. For the end interview data, a statistically significant association was found between level of understanding and approach to learning when considering the different levels of understanding in two groups split at the division between categories 4 and 5 (Kendall's taut $b=.516, p=.022$ ) and again between categories 5 and 6 (Kendall's taut $\mathrm{b}=.784, \mathrm{p}=.029$ ) but not between categories 3 and 4 (Kendall's tau- $\mathrm{b}=.302, \mathrm{p}=.515)$. With increased time spent learning about the concept of an IS, the empirical evidence supports the logical association between the deep learning approach and the deeper levels of understanding of an IS as a social system.

In summary, the findings support the existence of a significant statistical relationship between approach to learning about the concept of an IS and level of understanding developed. The relationship was found to have a particular nature. The deep approach to learning about IS identified in the study of Cope (2000a) was found to be associated with the greatest change in level of understanding, and the development of the levels of understanding that incorporated a limited number of social aspects of an IS.

The finding of a relationship between level of understanding and approach to learning is of great significance for teaching and learning about the concept of an IS. The nature of the relationship indicates that it is educationally critical for students to adopt a deep approach to learning about IS if a deep understanding of the concept of an IS as a social system is to be developed. Two questions arise from this finding. 1. What were the educationally critical characteristics of the deep learning approach identified in Cope (2000a) that lead to the development of the deeper levels of understanding? 2. Given that the deeper levels of understanding incorporated only limited aspects of an IS as a social system, what additional characteristics are critical if a full understanding of an IS as a social system is to be achieved? To address these questions the surface and deep learning approaches identified in Cope's (2000a) study were analyzed logically in the light of knowledge about learning approaches from the general student learning research.

In comparing the surface and deep learning approaches they can be seen to be mutually exclusive. The surface learning approach focused on learning tasks in isolation with the intention of recalling or applying the knowledge associated with tasks in assessment situations. The deep learning approach, in contrast, focused on seeking the meaning inherent in the various learning tasks encountered while studying about the concept of an IS. Meaning was sought through relating learning tasks in the same IS course, other IS courses, and other computing courses. The deep approach involved simultaneously considering the different perspectives on the concept of an IS generated in these multiple learning tasks, with the intention of generating the cohesive picture of an IS that was experienced as understanding.

Given that the concept of an IS as a social system is a complex, multi-facetted concept consisting of many related aspects, the surface learning approach is, logically, highly unlikely to develop the cohesive, related set of aspects of an IS that comprise a deep understanding. The relationships between the various aspects of an IS are not sought as part of this surface learning approach. An educationally critical characteristic of the deep learning approach, then, lies in the intention to seek an understanding of the concept of an IS. The process through which an understanding is sought is also an educationally critical characteristic. This is the process of seeking meaning in each learning task through trying to relate the learning tasks encountered in a number of IS and computing courses.

In the group of students studied, the deep learning approach resulted in only a limited number of social aspects of an IS becoming part of students' understandings. What is necessary in a learning approach to develop a full understanding of an IS as a social system? This full understanding incorporates knowledge beyond IT, which is knowledge about organizational activity, structure and behavior; how people communicate, attribute meaning to information and make organizational decisions; and how people interact with IT. It would seem logical that a deep approach that restricts perspectives on the concept of an IS to the IS course currently being studied and other IS and computing courses is not going to lead to the 
development of a deep understanding of an IS as a social system. It would seem educationally critical that meaning with regard to the concept of an IS is sought in an even broader range of perspectives, perspectives in courses in organizational behavior, for instance, and, importantly, perspectives in personal experiences of business organizations and information systems beyond the academic setting.

The incorporation of a broader range of additional perspectives on the concept of an IS into a deep learning approach requires an awareness by a student of their learning approach. Considering personal experiences, for instance, requires an intentional act on the part of the student. Why seek and incorporate these additional perspectives? The importance of the additional perspectives to the learning approach and to the deep understanding being sought must be recognized by the student. An awareness by a student of their own understanding of the concept of an IS and approach to learning about IS is, therefore, an educationally critical prerequisite to seeking additional perspectives and a critical characteristic of deep learning approach likely to lead the development of a deep understanding of an IS as a social system.

In summary, a logical analysis of the deep approach to learning about IS identified in Cope (2000a), and the nature of a deep understanding of an IS as a social system, has lead to the identification of the following educationally critical characteristics of a deep approach to learning about IS.

1. An intention to seek a deep understanding of the concept of an IS.

2. The process of seeking and relating the meanings associated with a broad range of different perspectives on the concept of an IS, including perspectives in personal experiences beyond the academic setting and in studies beyond IS and computing courses.

3. An awareness of one's own understanding of the concept of an IS and the approaches being used to learn about IS.

\section{Conclusion}

The study reported in this paper identified a statistically significant association between approach to learning and level of understanding of the concept of an IS. This finding allowed the description of some educationally critical characteristics of an approach to learning likely to lead to the development of a deep understanding of the concept of an IS as a social system of people making organizational decisions, supported by embedded IT. The characteristics identified centre on students being aware of and taking charge of their own approaches to developing a deep understanding of the concept of an IS.

The findings support, in a structured way, the many previous calls in the IS education research literature for a shift from knowledge transfer teaching approaches that focus on large student-number lectures (for example, Cope \& Horan, 1996). Instead, teaching approaches need to be student-centered, focusing on learning and assessment tasks that do the following:

1. provide a relevance structure for IS students that encourages the development of a deep understanding,

2. help students become aware of their current understanding of the concept of an IS and the limitations of their current level of understanding,

3. assist students to become aware of their current approaches to learning about IS and the limitations with their current approaches,

4. expose students to other approaches to learning about IS, approaches that incorporate a desire to gain a broad range of perspectives on the concept of an IS both within and outside the academic setting, and 
5. encourage students to seek meaning in the perspectives they experience through relating perspectives rather than considering each perspective as an isolated source of knowledge to be acquired for recall in assessment situations.

The development of these types of learning and assessment tasks presents a on-going challenge for IS education. Future research is needed that designs, implements and evaluates the impact of learning tasks that aim to encourage students to use deep approaches to learning about IS. Evaluation of students' learning approaches is not a difficult task. A number of generic questionnaires mentioned earlier in the paper are available, which can be easily modified to be applicable to IS education contexts.

\section{References}

Babinec, T., \& Mehta, C. (1999). Exploring exact statistics. Retrieved from http://www.spss.com/newsltrs/kw/Kw58/StatSpeak.html

Beynon-Davies, P. (1998). Information systems development (3rd ed.). London: MacMillan Press.

Biggs, J.B. (1987a). Student approaches to learning and studying. Hawthorn, Vic.: Australian Council for Educational Research.

Biggs, J.B. (1987b). Study process questionnaire. Manual. Melbourne: Australian Council for Education Research.

Biggs, J.B. (1999). Teaching for quality learning at University. Buckingham, U.K.: Open University Press.

Booth, S.A. (1992). Learning to program: A phenomenographic perspective. Göteborg Studies in Educational Sciences, 89. Göteborg: Acta Universitatis Gothoburgensis.

Booth, S.A. (1997). On phenomenography, learning and teaching. Higher Education Research and Development, 16 (2), 135 157.

Bowden, J., D’All'Alba, G., Martin, E., Masters, G., Laurillard, D., Marton, F., Ramsden, P., \& Stephanou, A. (1992). Displacement, velocity and frames of reference: Phenomenographic studies of students' understanding and some implications for teaching and assessment. American Journal of Physics, 60, 262-268.

Callaos, N. \& Callaos, B. (2002). Towards a systematic notion of information: Practical consequences. Informing Science, 5 , (1), $1-11$.

Cooper, D.R., \& Schindler, P.S. (1998). Business research methods (6th ed.). Boston, US: McGraw-Hill.

Cope, C.J. (2000a). Educationally critical aspects of the experience of learning about the concept of an information system. Unpublished $\mathrm{PhD}$ thesis . Retrieved fromhttp://ironbark.bendigo.latrobe.edu.au/staff/cope/cope-thesis.pdf

Cope, C.J. (2000b). Educationally critical aspects of a deep understanding of the concept of an information system. Proceedings of the Fourth Australasian Computing Education Conference, (pp. 48-55), New York: ACM.

Cope, C.J. (2002a). Educationally critical aspects of the concept of an information system, Informing Science Journal, 5, 6778.

Cope, C.J. (2002b). Seeking meaning: The educationally critical aspect of learning about information systems. Proceedings of the Informing Science \& IT Education Conference, Cork, Ireland, (pp. 305-319). Informing Science Institute.

Cope, C.J. \& Horan, P. (1996). The role played case: An experiential approach to teaching introductory information systems development. Journal of Information Systems Education, 8 (2\&3), 33-39.

Crawford, K., Gordon, S., Nicholas, J., \& Prosser, M. (1994). Conceptions of mathematics and how it is learned: The perspectives of students entering university. Learning and Instruction, 4, 331-345.

Crawford, K., Gordon, S., Nicholas, J., \& Prosser, M. (1998). Qualitatively different experiences of learning mathematics at university. Learning and Instruction, 8, 455-468.

Eizenberg, N. (1988). Approaches to learning anatomy: Developing a programme for preclinical medical students. In P. Ramsden (Ed.), Improving learning. New perspectives (pp. 178-198). London: Kogan Page.

Entwistle, N. J., \& Ramsden, P. (1983). Understanding student learning. London: Croom Helm. 


\section{Educationally Critical Characteristics of Deep Approaches}

Falkenberg, E.D., Hesse, W., Lindgreen, P., Nilsson, B.E., Han Oei, J.L., Rolland, C., Stamper, R.K., Van Assche, F.J.M., Verrijn-Stuart, A.A., \& Voss, K. (1996). A Framework of Information Systems Concepts. Report of the IFIP WG 8.1 Task Group FRISCO.

Gay, L.R. (1992). Educational research competencies for analysis and application (4th ed.). New York: Maxwell McMillan.

Hazel E. \& Prosser M. (1994). First-year university students' understanding of photosynthesis, their study strategies and learning context. The American Biology Teacher, 56, 274-279.

Hazel, E., Prosser, M., \& Trigwell, K. (1996). Student learning of biology concepts in different university contexts. Research and Development in Higher Education, 19, 323-326.

Hazel, E., Prosser, M. \& Trigwell. K. (2002) Variation in learning orchestration in university biology courses. International Journal of Science Education, 24, 737-751.

Hodgson, V. (1984). Learning from lectures. In F. Marton, D. Hounsell, D. \& N.J. Entwistle (Eds.), The experience of learning (pp. 90-102). Edinburgh: Scottish Academic Press.

Horan, P. (2000). Using rich pictures in information systems teaching. Proceedings of the first International Conference on Systems Thinking in Management, (pp. 257-262), Geelong, Australia

Horan, P. (2002). A new and flexible graphic organiser for IS learning: The Rich Picture. Proceedings of Informing Science conference \& IT Education Conference, Cork, Ireland, (pp. 133-138). Informing Science Institute.

Johansson, B., Marton, F., \& Svensson, L. (1985). An approach to describing learning as change between qualitatively different conceptions. In A.L. Pines \& L.H.T. West (Eds.), Cognitive structure and conceptual change (pp. 233-258). New York: Academic Press.

Land, F. F. (1992). The information systems domain. In R. Galliers (Ed.), Information systems research: issues, methods and practical guidelines (pp. 6-13). Oxford, UK: Blackwell Scientific Publications.

Lybeck, L., Marton, F., Stromdahl, H., \& Tullberg, A. (1988). The phenomenography of the "Mole Concept" in chemistry. In P. Ramsden (Ed.), Improving learning. New perspectives (pp. 81-108). London: Kogan Page.

Marton, F., \& Booth, S. (1996). The learner's experience of learning. In D.R. Olson \& N. Torrance (Eds.), The handbook of education and human development: New models of learning, teaching and schooling, (pp. 534-564). Oxford: Blackwell.

Marton, F., \& Booth, S. (1997). Learning and awareness. Mahwah, NJ: Erlbaum.

Marton, F., \& Saljo, R. (1976). On qualitative differences in learning. I. Outcome and process. British Journal of Educational Psychology, 46, 4-11.

McCune V. \& Entwistle, N.J. (2000). The deep approach to learning: analytic abstraction and idiosyncratic development. Paper presented at the 'Innovations in Higher Education' conference, 30 August - 2 September 2000, Helsinki.

Prosser, M. (1994). A phenomenographic study of students' intuitive and conceptual understanding of certain electrical phenomena. Instructional Science, 22, 189-205.

Prosser, M., \& Millar, R. (1989). The how and what of learning physics. European Journal of Psychology in Education, 4, 513-528.

Prosser, M., \& Trigwell, K. (1999). Understanding learning and teaching: the experience in higher education. Philadelphia, PA: Society for Research into Higher Education \& Open University Press.

Renström, L., Andersson, B., \& Marton, F. (1990). Students' conceptions of matter. Journal of Educational Psychology, 82, 555-569.

Sandberg, J. (1994). Human competence at work: An interpretative approach. Göteborg: BAS.

Svensson, L. (1977). On qualitative differences in learning: III. Study skills and learning. British Journal of Educational Psychology, 47, 233-243.

Tait, H. and Entwistle, N. J. (1996). Identifying students at risk through ineffective study strategies. Higher Education, 31, 99-118.

Trigwell, and Prosser, M. (1991). Improving the quality of student learning: the influence of learning context and student approaches to learning on learning outcomes. Higher Education, 22, 251-266.

Winter, M.C., Brown, D.H., \& Checkland, P.B. (1995). A role for soft systems methodology in information systems development. European Journal of Information Systems, 4, 130-142. 


\section{Acknowledgements}

Dr Graeme Byrne, Department of Mathematics, La Trobe University, Bendigo, Australia provided expert advice on the statistical aspects of the research.

\section{Biography}

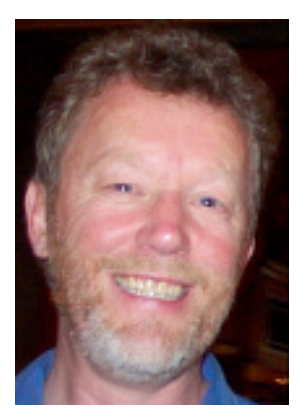

Chris Cope is an academic in the Department of Information Technology at La Trobe University, Bendigo, Australia. He has been teaching about IS to undergraduates and postgraduates for 17 years. His research interests are based around improving teaching about IS. To this end he has researched students' perceptions of their experiences of learning about information systems. This research has led to the implementation of changes to curriculum content and teaching approach. The changes are then evaluated in a structured way as a further research process. The research has been published in various conference proceedings, journal articles and book chapters. 